\title{
A BASE NACIONAL COMUM CURRICULAR DO ENSINO FUNDAMENTAL E O SEU GUIA DE IMPLEMENTAÇÃO: o simulacro da formação
}

\author{
Josele Fogaça \\ Rede Municipal de Educação de Inácio Martins - Brasil \\ Luciane Neuvald \\ Universidade Estadual do Centro-Oeste - UNICENTRO, Brasil
}

\begin{abstract}
Resumo
Objetiva-se a análise da Base Nacional Comum Curricular do Ensino Fundamental e do seu Guia de Implementação. Trata-se de uma pesquisa documental e bibliográfica, fundamentada na Teoria Crítica de Theodor Adorno, Max Horkheimer e Herbert Marcuse. A problemática define-se a partir da seguinte questão: Como a Base Nacional Comum Curricular (BNCC) e o seu Guia de Implementação expressam o simulacro da formação? Para responder a essa questão foram trabalhadas as concepções de formação e cultura. A tecnificação e a conciliação foram eleitas características que expressam as contradições do processo formativo intencionado pela BNCC, permitindo a compreensão de seu esquematismo e nivelamento, similar à indústria cultural. As análises revelam que os documentos estão em sintonia com a lógica da sociedade e, por isso, intencionam converter tudo ao mesmo denominador comum: o do fetiche da mercadoria. A renitência, por meio do exercício da crítica ao caráter universal desse fetiche, consiste em uma forma de quebra dos seus encantos.

Palavras-chave: Base Nacional Comum Curricular do Ensino Fundamental; Guia de Implementação da Base Nacional Comum Curricular do Ensino Fundamental; Educação; Semiformação; Teoria Crítica.
\end{abstract}

\begin{abstract}
This paper aims to analyze the Common Curricular National Base for Elementary School and its Implementation Guide. It is a documentary and bibliographical research, based on the Critical Theory of Theodor Adorno, Max Horkheimer and Herbert Marcuse. The problem is defined by the question: How does the Common Curricular National Base (CCNB) and its Implementation Guide shows the false education? To answer this question, the concepts of formation and culture were used. Technification and reconciliation were characteristics chosen because they express the contradictions of training process desired by the CCNB, allowing the understanding of its schemas and leveling, similar to cultural industry. The analyzes shows that the documents has the same logic of society and, therefore, convert everything to the same common denominator: that of the fetish of merchandise. Tenacity, through the exercise of criticism of the universal character of this fetish, refers a way of breaking its charms.
\end{abstract}

Keywords: Common Curricular National Base for Elementary School; Implementation Guide for the Common Curricular National Base for Elementary School; Education; Semiformation; Critical Theory. 


\section{Introdução}

Este artigo objetiva analisar a Base Nacional Comum Curricular do Ensino Fundamental (BNCC) e o seu Guia de Implementação, tendo como fundamento teórico a Teoria Crítica de Theodor Adorno, Max Horkheimer e Herbert Marcuse.

Para essa teoria, seja qual for o fenômeno estudado, ele não se desvincula da realidade na qual se insere. Tal pressuposto aponta para a compreensão da sociedade, especialmente diante do peso que ela exerce sobre os indivíduos, uma vez que "[...] não há nada, mas nada mesmo, sob o sol que, por ser mediado pela inteligência humana e pelo pensamento humano, não seja ao mesmo também mediado socialmente" (ADORNO, 2008, p. 72).

$\mathrm{Na}$ perspectiva adorniana (2008), a sociedade é concebida como uma categoria relacional, mediada e mediadora entre os seres humanos isolados. Ela não é um conceito absoluto para além deles, tampouco, reduz-se à soma ou aglomeração de pessoas. Sendo assim, os indivíduos e a sociedade devem ser pensados dialeticamente.

Portanto, não há indivíduos no sentido social do termo, ou seja, homens aptos à possibilidade de existir e existentes como pessoas, dotados de exigências próprias e, sobretudo, atuantes no trabalho, a não ser com referência à sociedade em que vivem e que forma os indivíduos em seu âmago. Por outro lado, também não há sociedade sem que seu próprio conceito seja mediado pelos indivíduos, pois o processo pelo qual ela se preserva é, afinal, o processo de vida, o processo de trabalho, o processo de produção e reprodução que se conserva mediante os indivíduos isolados, // socializados na sociedade (ADORNO, 2008, p. 119-120).

Adorno (2008, p. 122) compreende que uma Sociologia ou ciência da sociedade deve perseguir o essencial, ou seja, as leis objetivas do movimento da sociedade e suas tendências de desenvolvimento, dentre elas a de que "a sociedade capitalista só se conserva na medida em que expande". Com essas palavras, o autor referiu-se à necessidade que essa sociedade tem de ampliar o princípio do valor de troca para todas as esferas. A consideração desse aspecto é primordial para responder à problemática de como a BNCC e seu Guia de Implementação expressam o simulacro da formação.

A fim de obter tal resposta, este texto divide-se em três momentos. No primeiro deles, define-se a formação e a cultura, pois no entendimento da Teoria Crítica, essas concepções se inter-relacionam. No segundo momento, a BNCC e o seu Guia de Implementação são analisados a partir de uma de suas características mais expressivas: a tecnificação. No terceiro momento, discute-se outra característica: a da conciliação, que juntamente com a tecnificação compõe a racionalidade instrumental, que intenciona o ordenamento da objetividade social, na tentativa de controlá-la. 


\section{Formação e cultura}

A formação no âmbito da Teoria Crítica pressupõe o seu contrário, ou seja, a semiformação, a qual é compreendida por Adorno (2010) como o simulacro, como a falsificação da formação. Nesses termos, a formação converte-se em norma e em qualificação, orientando-se pelo realismo e pelo conformismo. Essa condição torna, segundo Adorno (2010, p. 9), o "espírito aprisionado pelas malhas da socialização", ou seja, pelos valores de troca, cuja ampliação se estende para todos os setores da vida. Assim, o espírito perde a sua capacidade crítica, cedendo lugar para a onipresença do espírito alienado.

Para Adorno (2010, p. 33) a semiformação simboliza a consciência que renunciou à autodeterminação e "O semiculto dedica-se à conservação de si mesmo sem si mesmo. Não pode permitir, então, o que, segundo a teoria burguesa, constituía a subjetividade: a experiência e o conceito". Sob essas condições, os bens culturais são classificados, seguindo a mesma fórmula e o mesmo padrão, A imitação se constitui em ideal absoluto e a semiformação objetiva a reconciliação entre coisas irreconciliáveis: a cultura e o entretenimento, o rigor e a profundidade, o contingencial e volúvel no lugar da solidez inerente à historicidade característica da cultura. Sendo assim, a semiformação anula a dimensão do trágico e da angústia, porque nelas se encontra a possibilidade da autocrítica e da reflexão.

Para Adorno (2010) e Marcuse (1998), a cultura e a formação se inter-relacionam e não se diferenciam. Ambas representam a resistência à lógica da sociedade, que é a da semiformação, ou seja, a da mercantilização e banalização da cultura. Sendo assim, a produção e consumo dos bens culturais seguem a mesma lógica da economia. Essa orientase pela produção em massa, em série, pela produção compacta e simplificada, com redução de tempo e de esforços. Seguindo a tendência de todos os bens da sociedade capitalista, os bens culturais prezam pela atração e mobilidade, pois essas características lhes permitem ampliar a propaganda da sociedade de consumo. Para o indivíduo, resta a ilusão de que suas escolhas são pessoais, quando, na verdade, elas são dirigidas pelo sistema.

Marcuse (1998) compreende a cultura como distinta da civilização, atribuindo à primeira uma dimensão superior, já que ela conserva a liberdade, autonomia e a realização humana, enquanto a segunda se orienta pelo mundo da necessidade. No texto "A dimensão estética" (1995), publicado no livro Eros e a civilização, Marcuse ressalta que o desenvolvimento da civilização, provoca um antagonismo entre ela e a cultura, entre o impulso formal (ativo e dominador) e o impulso sensual (essencialmente passivo e receptivo). Com o tempo, a civilização "[...] submeteu a sensualidade à razão de modo tal que a primeira, se acaso logra reafirmar-se, o faz através de formas destrutivas e 'selvagens', enquanto a tirania da razão empobrece e barbariza a sensualidade" (MARCUSE, 1995, p. 166).

No texto "Comentários para uma definição de cultura", ele define a cultura como

[...] um processo de humanização (Humanisierrung) caracterizado pelo esforço coletivo para conservar a vida humana, para pacificar a luta pela existência ou mantê-la dentro dos limites controláveis, para consolidar uma organização 
produtiva da sociedade, para desenvolver as capacidades intelectuais dos homens e para diminuir e sublimar a agressão, a violência e a miséria (MARCUSE, 1998, p, 153-154).

A referida concepção de cultura expressa que ela é fundamental para a humanidade, evitando a expansão da barbárie. Sendo assim, a tensão entre a cultura e a esfera da vida material dificulta a integração promovida pela sociedade totalitária, cuja característica ameaça até mesmo as instituições democráticas, conforme alerta Marcuse (1998).

Além disso, a égide dos valores de troca agrava a possibilidade de o pensamento se ajustar ao existente e de enfraquecer o seu aspecto crítico. Na concepção de Marcuse (1998), a felicidade não sucumbe à autoconservação, a qual demanda a subsunção do espírito à realidade. Ao contrário, ela exalta a promoção da cultura, cuja essência não é operacional e tem na tradição anterior à civilização industrial, a sua representatividade, na medida em que nessa o espírito resiste à ordem existente e transcende ao imediato.

$\mathrm{Na}$ concepção de Adorno (2010), a cultura tradicional opõe-se à semiformação socializada, o que o faz relacionar essa última à perda da tradição, à carência de imagens e de formas, à devastação do espírito, na medida em que ele se torna um meio.

As condições da própria produção material dificilmente toleram o tipo de experiência sobre a qual se assentavam os conteúdos formativos tradicionais que se transmitiam. Por isso, tudo o que estimula a formação acaba por lhe contrair os nervos vitais (ADORNO, 2010, p. 17).

O espírito se torna um meio quando, de acordo com Adorno (2010, p. 21-22), o "pretenso realismo sucede o homem de espírito". O realismo representa o mundo exterior, os apelos imediatos e as necessidades do todo (da sociedade). Ao contrário dele, o espírito representa a possibilidade de diferenciação, de mediaticidade e de resistência aos apelos da sociedade. Tal fato justifica o alerta do autor para a necessidade de se proteger das atrações do mundo exterior e de conservar lacunas de socialização - de adesão ao coletivo - o que exige do sujeito ponderado, que prime pela sua autonomia (entendida como capacidade de autorreflexão crítica) e pela sua singularidade (resistência à identificação, preservação do processo de não identificação com a lógica da sociedade, de resistência à integração).

Os mecanismos do domínio social da natureza e sua busca pelo controle, pela exatidão, pela utilidade e instrumentalismo distinguem-se da formação cultural, ameaçando-a. Esse fato acontece, segundo Adorno (2010, p. 23), porque nessa perspectiva, a formação se transforma em algo controlável, em norma e em qualificação. Assim, enfraquece o tempo, a memória e os pressupostos, cujos elementos a caracterizam: "Nada do que, de fato, se chame formação poderá ser aprendido sem pressupostos” (ADORNO, 2010, p. 30).

A formação, no entendimento de Adorno (2010, p.21) é similar ao processo identificatório com a figura paterna, descrito por Freud, o qual estabelecia uma relação entre esse processo, a autonomia e o princípio do ego. Essa identificação inicial serve de base para que, posteriormente, os filhos contraponham a irracionalidade das relações familiares. Essa 
compreensão valida o vínculo que Adorno estabelece entre a formação e os pressupostos, ou seja, entre a formação e um referencial identificatório, cuja matriz apresente solidez.

No entanto, Adorno não ignora que a cultura remete à sociedade, pois na Teoria da semiformação (2010), ele fala do duplo caráter da cultura, que surge da necessidade de resolver o antagonismo social não conciliado, ou seja, o conflito entre adaptação (mundo material e das necessidades e da sobrevivência) e o mundo espiritual (que transcende o imediatismo e envolve o pensamento, a reflexão e a autonomia do indivíduo frente aos apelos exteriores). $\mathrm{O}$ autor destaca os riscos de se compreender a cultura e a formação sob o âmbito de categorias fixas, sejam elas de adaptação ou de transcendência. Para Adorno (2010), a cultura e a formação se constituem em um campo de forças, em um processo que deve primar pela tensão e pela constante vigilância de uma sobre a outra.

Quando o campo de forças a que chamamos formação se congela em categorias fixas - sejam elas do espírito ou da natureza, de transcendência ou de acomodação -, cada uma delas, isolada, se coloca em contradição com seu sentido, fortalece a ideologia e promove uma formação regressiva (ADORNO, 2010, p. 11).

As obras de arte, na concepção adorniana, constituem-se em referencial de formação e de resistência aos processos regressivos promovidos pela organização social. Ao não se reduzir ao exterior e manter o distanciamento e a tensão com o objeto que quer expressar, a arte resiste aos apelos identificatórios e à integração à sociedade; ou seja, resiste ao princípio da troca de equivalentes que se orienta pelo consumo. Assim, Adorno (1993, p.125) entende que toda figura clara faz concessões ao consumo, já que intenciona a unidade, o enquadramento e a reconciliação entre o pensamento e a realidade, característicos do instrumentalismo.

A liberdade da arte está na sua capacidade de postular o não existente e de colocá-lo em conflito com a sua não existência real. Ela só existe a partir da negação, da busca da verdade que é possível apenas naquilo que não se harmoniza com o mundo, pois a identidade estética pressupõe a não identidade diante da compulsão à identidade promovida pela realidade opressiva (ADORNO, 2006, p. 74).

Adorno destaca na Dialética Negativa (2009, p. 19-24), a relação entre a arte e a filosofia, na medida em que ambas apresentam uma compromisso com a expressão e com a apresentação - o que o leva a afirmar a relação entre o que é dito de modo frouxo e o mal pensado. Portanto, a arte comporta a autonomia, o rigor e a fidelidade à sua ideia. Sendo assim, ela não se deixa levar pelas contingências e pela lógica do pensamento classificatório e adepto à padronização, seguido pela totalidade social.

Em seu livro Eclipse da razão, Horkheimer (2002, p. 9) destaca que o aspecto subjetivo da razão consiste em sua capacidade de classificar, inferir e decidir, ou seja, ao "funcionamento abstrato do mecanismo de pensamento". Assim, a fonte da razão está no sujeito, cujas estruturas do pensamento organizam a realidade, nominando-a. O nominalismo é citado por Adorno e Horkheimer (1985) como uma característica da razão que se abstrai da realidade, reduzindo sua polissemia por meio do conceito. Essa razão é de característica 
instrumental e pressupõe a tecnificação. Seus diferentes sentidos são identificados e analisados no contexto da BNCC e do seu Guia de Implementação, a seguir.

\section{A tecnificação na BNCC do Ensino Fundamental e do seu Guia de Implementação}

A análise da BNCC do Ensino Fundamental e do seu Guia de Implementação apresenta uma série de termos corolários à tecnificação do ensino. A escolha dessa característica considerou que o discurso presente nesses documentos não é arbitrário, aleatório e apriorista, mas é o resultado de um conjunto de relações e de interesses sociais, que sustentam uma determinada racionalidade. Essa, por sua vez, "[...] é construída como conhecimento que ordena os elementos oferecidos pelas evidências empíricas" (EVANGELISTA, 2012, p. 59).

A racionalidade da BNCC e do seu Guia de Implementação é de característica instrumental e correlata da tecnificação, pois assim como essa última, valoriza a especialização, o aspecto operacional e prático.

$\mathrm{Na}$ sua apresentação, o documento da BNCC (2018, p.5) intitula-se completo e contemporâneo, elaborado por especialistas de todas as áreas do conhecimento. Ele aspira ao atendimento das demandas atuais dos estudantes, preparando-os para o futuro e entende a contemporaneidade como a sintonia com tendências que apontam para o valor econômico da educação e para o centralismo representado pela orientação das agências internacionais.

[...] avaliações internacionais da Organização para a Cooperação e Desenvolvimento Econômico (OCDE), que coordena o Programa Internacional de Avaliação de Alunos (Pisa na sigla em inglês), e da Organização das Nações Unidas para a Educação, a Ciência e a Cultura (Unesco, na sigla em inglês), que instituiu o Laboratório Latino-americano de avaliação da Qualidade da Educação para a América Latina (LLECE, na sigla em espanhol) (BRASIL, 2018, p. 13).

Essas condições diminuem o que Adorno (2010) intitula de lacunas de socialização, nas quais se visualiza a possibilidade de resistência ao excesso de realismo, à adesão das partes (nesse caso, estudantes, professores e escolas), ao todo, representado pela política econômica e educacional. Essas políticas não se desvinculam da objetividade social, mediadora de todas as relações sociais, ou seja, dos valores de troca. Sendo assim,

As condições da própria produção material dificilmente toleram o tipo de experiência sobre a qual se assentavam os conteúdos formativos tradicionais que se transmitiam. Por isso, tudo o que estimula a formação acaba por lhe contrair os nervos vitais (ADORNO, 2010, p. 17).

Conforme a BNCC (2018, p. 14), no novo cenário mundial, reconhecer-se em seu contexto histórico e cultural, comunicar-se, ser criativo, analítico-crítico, participativo, aberto ao novo, colaborativo, resiliente, produtivo e responsável requer muito mais do que o 
acúmulo de informações. Ou seja, requer o desenvolvimento de competências para aprender a aprender, saber lidar com a informação cada vez mais disponível, atuar com discernimento e responsabilidade nos contextos das culturas digitais, aplicar conhecimentos para resolver problemas, ter autonomia para tomar decisões, ser proativo para identificar os dados de uma situação e buscar soluções, conviver e aprender com as diferenças e as diversidades.

A análise desse pressuposto da BNCC incide sobre duas considerações. A primeira delas toma como referência o que a BNCC entende por ser criativo, pois no contexto de seu discurso, essa palavra pressupõe inovação e se associa a outros termos por ela citados: capacidade de resolução de problemas e resiliência - os quais se associam à lógica instrumental voltada para a razão objetiva e prática, capaz de enfrentar adversidades e de ser flexível, promovendo, assim, o princípio da adaptação.

Nas entrelinhas desse discurso está a exaltação da competitividade, a qual, no entendimento de Adorno (1995), é um princípio contrário a uma educação humana.

De resto, acredito também que um ensino que se realiza em formas humanas de maneira alguma ultima o fortalecimento do instinto de competição. Quando muito é possível educar desta maneira esportistas, mas não pessoas desbarbarizadas. Em minha própria época escolar, lembro que nas chamadas humanidades a competição não desempenhou papel algum. O importante era realizar aquilo que se tinha aprendido; por exemplo refletir acerca das debilidades do que a gente mesmo faz; ou as exigências que colocamos para nós mesmos ou à objetivação daquilo que imaginávamos; trabalhar no sentido de superar representações infantis e infantilismos dos mais diferentes tipos (ADORNO, 1995, p.161-162).

A BNCC também menciona a capacidade analítico-crítico, a qual significa o julgamento e o critério de decomposição do todo em partes mais simples, a fim de explicar com mais facilidade e de se atingir maior clareza, o que no entendimento de Adorno (1993), pressupõe concessões ao consumo, ou seja, àquilo que é gasto e utilizável. Assim, a clareza é sinônimo de comunicabilidade, de objetividade e de diretividade. Nesses termos, a figura é corrompida pela inclusão do interlocutor, ou seja, a ideia é sacrificada em função de sua exterioridade, que é a comunicação. A clareza faz concessões ao consumo.

Apesar de a BNCC não sugerir explicitamente ordem e hierarquia em seu texto e de seus objetivos se repetirem em uma mesma etapa, não se pode negar a presença de uma perspectiva de ordenamento e classificação, expressa no estabelecimento dos objetivos de aprendizagem e de desenvolvimento. A BNCC aponta para uma concepção cronológica do tempo, para a necessidade de dominá-lo, a fim de que ele seja utilizado nos moldes de uma sequência pré-estabelecida. Este aspecto pode ser exemplificado a partir do uso de códigos como este: (EF15LP01), que significa Ensino Fundamental, primeiro a quinto ano, Língua Portuguesa, habilidade de número um (BRASIL, 2018, p.95).

Conforme a BNCC:

[...] é preciso enfatizar que os critérios de organização das habilidades do Ensino Fundamental na BNCC (com a explicitação dos objetos de conhecimento aos 
quais se relacionam e do agrupamento desses objetos em unidades temáticas) expressam um arranjo possível (dentre outros). Portanto, os agrupamentos propostos não devem ser tomados como modelo obrigatório para o desenho dos currículos. Essa forma de apresentação adotada na BNCC tem por objetivo assegurar a clareza, a precisão e a explicitação do que se espera que todos os alunos aprendam no Ensino Fundamental, fornecendo orientações para a elaboração de currículos em todo o País, adequados aos diferentes contextos (BRASIL, 2008, p. 31).

O fato de não se colocar como modelo, mas como uma orientação (conforme citação anterior), fica diluído pela força que a representação numérica e o detalhamento das habilidades exercem. A busca pela clareza, pela precisão e pela explicitação dos objetivos assume expressão significativa, inibindo a possibilidade de pensar muito além do exposto, pois o documento se antecipa a qualquer tentativa de pensamento, assumindo o papel do sujeito no esquematismo kantiano - o que leva a estabelecer uma analogia entre essa característica da lei e a análise da indústria cultural, realizada por Adorno e Horkheimer na Dialética do esclarecimento (1985).

A segunda consideração acerca da BNCC refere-se à promoção da pedagogia das competências, a qual, segundo Duarte (2001) integra uma ampla corrente educacional contemporânea denominada de pedagogias do "aprender a aprender", na qual a lógica do treinamento (coaching) sobrepõe-se à lógica do ensino. Nesse contexto a construção de competências ocorre por meio do exercício, em situações complexas.

Duarte (2001, p. 36) destaca algumas ilusões das pedagogias do "aprender a aprender", dentre elas a da priorização do "[...] método de aquisição, elaboração, descoberta, construção de conhecimentos, em detrimento de o aluno aprender os conhecimentos que foram descobertos e elaborados por outras pessoas". Assim, o método científico é mais importante do que o conhecimento científico.

O autor (2001) também ressalta que as pedagogias do “aprender a aprender" valorizam a atividade da criança como motor do conhecimento e a necessidade de preparar os indivíduos para as mudanças aceleradas da sociedade, pois essa pedagogia entende que a educação tradicional, devido à sua característica estática, não teria aptidão para fazê-lo. Dessa forma,

[...] a nova educação deve pautar-se no fato de que vivemos em uma sociedade dinâmica, na qual as transformações em ritmo acelerado tornam os conhecimentos cada vez mais provisórios, pois um conhecimento que hoje é tido como verdadeiro pode ser superado em poucos anos ou mesmo em alguns meses. O indivíduo que não aprender a se atualizar estará condenado ao eterno anacronismo, à eterna defasagem de seus conhecimentos (DUARTE, 2021, p. 37).

Duarte (2001) critica o caráter adaptativo dessa pedagogia, que impossibilita a crítica e a transformação social, uma vez que os educadores precisam conhecer a realidade para modelar a sua conduta. 
O caráter adaptativo dessa pedagogia está bem evidente. Trata-se de preparar aos indivíduos formando as competências necessárias à condição de desempregado, deficiente, mãe solteira etc. Aos educadores caberia conhecer a realidade social não para fazer a crítica a essa realidade e construir uma educação comprometida com as lutas por uma transformação social radical, mas sim para saber melhor quais competências a realidade social está exigindo dos indivíduos. Quando educadores e psicólogos apresentam o "aprender a aprender" como síntese de uma educação destinada a formar indivíduos criativos, é importante atentar para um detalhe fundamental: essa criatividade não deve ser confundida com busca de transformações radicais na realidade social, busca de superação radical da sociedade capitalista, mas sim criatividade em termos de capacidade de encontrar novas formas de ação que permitam melhor adaptação aos ditames da sociedade capitalista (DUARTE, 2001, p. 38).

As análises de Duarte, embora não se pautem na Teoria Crítica, comungam com essa última, na medida em que ambas apontam o aspecto adaptativo que incide sobre os rumos da educação na atualidade. No âmbito da Teoria Crítica, a valorização do sujeito e dos processos de conhecimento característica das pedagogias do "aprender a aprender", encobre uma lógica social totalitária, que torna a adaptação automática, conforme afirma Adorno (1995). Dessa forma, uma educação emancipatória reverbera sobre essa questão e questiona o aspecto fundante do processo educativo, que está para além das demandas do mundo exterior, já que pressupõe o desenvolvimento da capacidade de autorreflexão crítica dos seres humanos, comprometida pelo poder da sociedade sobre os indivíduos.

A submissão da educação às mudanças aceleradas da sociedade constitui-se em uma ameaça à formação, a qual remete a estruturas previamente colocadas, sendo que a carência de imagens, de formas e de uma tradição torna-se incompatível com a formação compreendida nos termos adornianos. Adorno (2010) destaca a importância da tradição, concebendo-a analogamente à autoridade da figura paterna. Ele ressalta a ocorrência de alguns abusos em relação ao conceito de autoridade, pois:

O modo pelo qual - falando psicologicamente - nos convertemos em um ser humano autônomo, e portanto emancipado, não reside simplesmente no protesto contra qualquer tipo de autoridade (ADORNO, 1995, p.176-177).

A educação a serviço da sociedade, na qual impera a razão dominadora, submete-se à pressão do mundo. Por isso, Adorno (2010, p. 39) destaca a necessidade de reafirmar que o espírito não se reduz à dependência das relações reais de vida e se conforma ao papel de mero meio, que há um momento de verdade na capacidade do espírito para se separar das relações de vida. Assim, o

[...] conceito de racionalidade ou de consciência é apreendido de um modo excessivamente estreito, como capacidade formal de pensar. Mas esta constitui uma limitação da inteligência [...]. Mas aquilo que caracteriza propriamente a consciência é o pensar em relação à realidade, ao conteúdo - a relação entre as 
formas e estruturas de pensamento do sujeito e aquilo que este não é. Este sentido mais profundo de consciência ou faculdade de pensar não é apenas o desenvolvimento lógico formal, mas ele corresponde literalmente à capacidade de fazer experiências. Eu diria que pensar é o mesmo que fazer experiências intelectuais. Nesta medida e nos temos que procuramos expor, a educação para a experiência é idêntica à educação para a emancipação (ADORNO, 1995, p. 151).

O documento da BNCC (2020) procura contemplar a cultura digital, as diferentes linguagens e os diferentes letramentos; tanto aqueles considerados como lineares, isto é, com baixo nível de hipertextualidade como aqueles que envolvem a hipermídia.

A consideração dos novos e multiletramentos; e das práticas da cultura digital no currículo não contribui somente para que uma participação mais efetiva e crítica nas práticas contemporâneas de linguagem por parte dos estudantes possa ter lugar, mas permite também que se possa ter em mente mais do que um "usuário da língua/das linguagens", na direção do que alguns autores vão denominar de designer: alguém que toma algo que já existe (inclusive textos escritos), mescla, remixa, transforma, redistribui, produzindo novos sentidos, processo que alguns autores associam à criatividade. Parte do sentido de criatividade em circulação nos dias atuais ("economias criativas", "cidades criativas" etc.) tem algum tipo de relação com esses fenômenos de reciclagem, mistura, apropriação e redistribuição (BRASIL, 2020, p. 70).

Esse excerto da BNCC atenta para três aspectos: o do multiletramento, o da cultura digital e a concepção de designer no processo de produção de novos sentidos. Os dois primeiros conceitos remetem às análises de Fuzal e Mirandall (2020), que analisam as concepções da BNCC sobre letramentos, tecnologias digitais e gêneros discursivos nas diferentes áreas do documento.

As autoras questionam a forma de utilização da palavra letramento pela BNCC, ou seja, dentro de suas especificidades, focada no saber teórico das áreas e vinculada à atribuição de adjetivos, dentre eles: "letramento científico", "letramento matemático", "Multiletramentos". Na concepção de Fuzal e Mirandall (2020), a adjetivação não expressa o sentido do termo "letramento", o qual, no entendimento das autoras, remete à prática social da língua, aos seus contextos de uso, ao invés de um conjunto de habilidades e competências, empregadas de maneira autônoma e desvinculada do aspecto ideológico.

Fuzal e Mirandall (2020), ao buscarem na BNCC pelas palavras-chave "digital/digitais", associadas ou não a "tecnologia/tecnologias", constataram o número de 248 ocorrências. Diante desse fato, preocupam-se com os efeitos da intensa proposição de uso e produção de tecnologias digitais nos trabalhos de sala de aula e com os impactos para o trabalho e a formação docente.

A tecnologia como linguagem mediadora e espinha dorsal do processo de ensinoaprendizagem é uma tendência da BNCC. Ao se levantar as habilidades organizadas por 
componentes curriculares, obteve-se o seguinte resultado: Língua Portuguesa - 192 habilidades e dessas 38 mencionam as tecnologias; Arte- 26 habilidades e uma menciona o uso da tecnologia; Educação Física - 28 habilidades e nenhuma menção às tecnologias; Matemática - 126 habilidades e 6 mencionam as tecnologias; Ciências - 35 habilidades e uma menciona as tecnologias; Geografia - 56 habilidades e uma menciona a tecnologia; História - 46 habilidades e 3 mencionam as tecnologias; Ensino Religioso - 33 habilidades e nenhuma menciona as tecnologias. Em um total de 542 habilidades, 50 mencionam a tecnologia.

Marcuse (1999) compreende a tecnologia como forma de organização socioeconômica associada a uma determinada etapa de desenvolvimento das forças produtivas e das relações de produção. Ela é vista como a totalidade de instrumentos, dispositivos e invenções que caracterizam a era da máquina e consiste em uma manifestação do pensamento e dos padrões de comportamento dominantes, um instrumento de controle e de dominação.

A racionalidade tecnológica, no entendimento de Marcuse (1999), é corolária da eficiência competitiva, que favorece as empresas com equipamento industrial mais altamente mecanizado e racionalizado. Ela permite a organização e a coordenação dos indivíduos em larga escala. Ao suavizar a luta pela existência, a tecnologia, segundo Marcuse (1973), contribui para tornar a sociedade coesa e integrada, para aplanar os contrastes e despotencializar a crítica. A tecnologia, ao mediar as relações entre os seres humanos, intercepta a sua libido dos indivíduos, dirigindo-a para o seu aparato.

Essas ponderações contribuem para problematizar a evidência que a BNCC confere à tecnologia, especialmente quando se coloca em discussão o contexto que a propulsiona (a sociedade capitalista) e a amplitude que ela assume com a sua forma digital de comunicação, que facilita o acesso, na medida em que os indivíduos podem usar a internet por meio de um dispositivo móvel, que cabe na palma da mão.

A tecnologia vista como o elemento integrador do ensino, é compatível com a ideia de designer, utilizada pela BNCC, para se referir às práticas de linguagens. Essas, por meio da tecnologia digital, apresentam uma diversidade de sentidos, cuja apropriação, recorte, colagem, esquematização e elaboração criativa ampliam a capacidade de aprendizagem, ou seja, a capacidade de mobilizar informações - o que coloca em questão o papel da escola como lugar do conhecimento científico.

No Dicionário Online de Português, designer refere-se ao indivíduo que planeja ou concebe um projeto ou modelo, que trabalha com a criação e projeção de um produto. Notase que o termo refere-se à produção industrial e à funcionalidade. Dessa forma, o processo de conhecimento e a sua utilidade assumem destaque na BNCC.

Ao comentar sobre a educação integral (2018, p. 14), a BCNN aborda as seguintes questões: o que aprender, para que aprender, como ensinar e como promover redes de aprendizagem colaborativa. Nota-se aqui a ausência da questão relacionada ao o que ensinar e como aprender. Esses aspectos convergem para a problematização do papel do professor, subsumido à tarefa de implementação da proposta da BNCC, que dilui o ensinar no processo de aprendizagem, cujas habilidades e competências estão previamente definidas. O silenciamento do para que ensinar é revelador, pois indica que o professor tem um papel mais 
importante no contexto da implementação das políticas curriculares, objetivando-a em sua prática pedagógica, considerando as orientações dos especialistas e das equipes selecionadas para a adaptação da BNCC nos contextos estaduais e municipais.

A ausência do como aprender também é reveladora, uma vez que fica subentendido que essa questão foi previamente antecipada pelos especialistas, que já organizaram-na no âmbito dos materiais, dos cursos e dos suportes técnicos de implementação da BNCC. Nota-se a escassez de fundamentação teórica do documento, especialmente quando se refere às concepções de homem, sociedade, conhecimento.

A relevância assumida por especialistas e autoridades em assuntos específicos, não é exclusiva da BNCC, pois o Guia Curricular também valoriza esse aspecto. A esses profissionais atribui-se a responsabilidade intelectual, organizacional, formadora e avaliadora de todos os processos, os quais demandam um planejamento e detalhamento de todas as ações.

O Guia Curricular (2020) apresenta sete dimensões para orientar o processo de implementação da BNCC, que estão organizadas em um percurso que visa facilitar o trabalho das secretarias: 1. Estruturação da governança da implementação; 2. Estatuto das Referências Curriculares; 3. (RE) elaboração curricular; 4 .Formação continuada para os novos currículos; 5. Revisão dos projetos pedagógicos; 6. Materiais didáticos; 7. Avaliação e acompanhamento da aprendizagem (BRASIL, 2020, p. 3).

De acordo com o Guia (2020, p. 10 -11), a governança expressa modelo de colaboração, cuja estrutura sugerida consiste na equipe da gestão - coordenadores estaduais da BNCC, analista de gestão, articulador de regime de colaboração. Também consiste em uma equipe de currículo: coordenadores de etapas, especialistas consultores, redatores de currículo, membros selecionados dos GTs e outros indicados pelo CONSED (Conselho Nacional de Secretários de Educação) e pela UNIDIME (União Nacional dos Dirigentes Municipais de Educação).

O documento (2020, p 12) demonstra preocupação com a clareza e o ritmo do processo, com os recursos e o cronograma, a importância da previsão de recursos. Ele ressalta que entre os atores que podem oferecer recursos adicionais estão especialistas, universidades, organizações da sociedade civil, conselhos e órgão governamentais.

Conforme as orientações do Guia (2020, p. 13), as secretarias estaduais e seccionais da UNDIME que aderirem ao Programa de Apoio à Implementação, necessitarão do planejamento específico da alocação do recurso que será disponibilizado para a UF (Unidade da Federação). Indicam-se questões norteadoras podem auxiliar o planejamento e a alocação dos recursos, dentre elas: a contratação de especialistas e a realização de eventos formativos e de mobilização.

Dentre as ações que compõem a integração da governança, está a nomeação de uma equipe responsável pela (re)elaboração curricular, que determinará os papeis e responsabilidades definidos no planejamento, trabalhando no sentido de garantir a gestão do processo e os objetivos de (re)elaboração e implementação curricular. A composição dessa equipe abrange, conforme o Guia (2020, p 17): 1 Coordenador estadual de currículo da secretaria estadual e outro da seccional da UNDIME; 1 Articulador de regime de colaboração, 
por seccional da UNDIME; 1 Analista de gestão por estado; 3 Coordenadores curriculares de etapa de ensino (1 para Educação Infantil, 1 para Anos Iniciais e 1 para Anos Finais do Ensino Fundamental); 22 Redatores do currículo.

Na concepção do referido documento (2020, p. 18), a mobilização e a comunicação são fundamentais para o sucesso da implementação, pois "Essa estratégia confere legitimidade ao processo e ao resultado, evita resistências e apoia os professores das escolas públicas e privadas a colocar o novo documento curricular em prática na sala de aula”.

A respeito dessa primeira dimensão, da governança, faz-se necessário destacar três aspectos que elucidam os interesses e concepções presentes. O primeiro deles refere-se à gestão, a qual, no contexto do Guia Curricular, não lembra os princípios democráticos, pois se parece muito com o modelo empresarial de organização de uma logística, divisão de tarefas, controle de processos e de resultados, a fim de atingir metas e objetivos elaborados por uma equipe de especialistas. Nesse sentido, a gestão fortalece a hierarquia de poderes e o controle sobre os subordinados.

O segundo aspecto recai sobre a ênfase na compreensibilidade da proposta curricular, sobre a necessidade de torná-la clara e acessível e legítima. Sobre a clareza, anteriormente, destacou-se como ela é vista de forma suspeita pela abordagem adorniana, cujo olhar mostra a intenção do Guia em enfraquecer a autonomia e o protagonismo dos professores. A clareza também é uma forma de legitimar o consentimento e de evitar resistências.

A necessidade do consenso e da integração da proposta anula a tensão e o debate, fundamentais para a construção de uma educação emancipatória. Na concepção de Adorno e Horkheimer (1985), a falsa clareza, caracteriza a racionalidade burguesa, pois a busca pela unidade, pela calculabilidade do mundo e pela familiaridade, impede-a do trabalho teórico e da autocrítica. Ela é uma forma de colocar a linguagem a serviço da ordem existente. Para eles,

A falsa clareza é apenas uma outra expressão do mito. Este sempre foi obscuro e iluminante ao mesmo tempo, Suas credenciais têm sido desde sempre a familiaridade e o fato de dispensar do trabalho e do conceito (ADORNO; HORKHEIMER, 1985, p.14).

O terceiro aspecto que compõe a análise da dimensão do item Estruturação da governança da implementação, refere-se ao planejamento e à racionalização dos recursos financeiros e humanos, no qual se manifesta a característica da identificação antecipatória da racionalidade burguesa, que assim pretende estar à salva do mito. No entanto, assume a forma mítica ao abstrair-se, ao renegar a autorreflexão crítica e a tensão entre o pensamento e a realidade, que caracteriza a razão emancipatória.

Adorno e Horkheimer (1985, p. 14), estabelecem relação entre o aumento da quantidade de bens destinados às massas e o aumento da injustiça, da impotência e da dirigibilidade sobre elas. Assim, sob o pretexto de melhorar a qualidade do ensino e desenvolver habilidades e competências, a BNCC e o se Guia de implementação, por meio de seu aparato 
técnico, reúnem em um cadinho tudo que consideram fundamental na composição da formação dos indivíduos.

Se a cultura respeitável constituía até o século dezenove um privilégio, cujo preço era o aumento do sofrimento dos incultos, no século vinte o espaço higiênico da fábrica teve por preço a fusão de todos os elementos da cultura num cadinho gigantesco (ADORNO; HORKHEIMER, 1985, p.14).

A dimensão de número dois, que sucede a da governança, é a do Estatuto das Referências curriculares. Nela,

a equipe gestora do processo e as equipes pedagógicas dedicam-se a estudar conceitos e concepções fundamentais para a (re)elaboração curricular como, por exemplo, a BNCC e a articulação com os demais documentos existentes (a exemplo dos Projetos Pedagógicos - PPs das escolas); os referenciais teóricos; os diferentes tipos de documentos curriculares; as implicações do formato navegável e editável e abordagens; e as metodologias para uma (re)elaboração curricular (BRASIL, 2020, p. 21).

A dimensão de número três consiste na (RE)elaboração curricular, segundo o Guia (2020, p 24-26), compreende a organização de professores a fim de discutir, aprofundar e desenvolver o documento curricular, estruturado a partir da BNCC, reelaborado pelos Estados, objetivados pelo Projeto Pedagógico das escolas, pelo plano de aula professor, culminando no produto: "estudante com alto nível de aprendizagem". Essa terminologia indica que o termo conhecimento é preterido pelo termo aprendizagem - o que expressa a perspectiva subjetivista e individualista do pensamento liberal. Esse acredita que o indivíduo apto a usar suas capacidades de aprendizagem, poderá ampliá-las, especialmente em um contexto de ampliação da internet.

Como estratégia de implementação da etapa de número três, o Guia recomenda a composição de grupos de trabalho, sendo que "[...] o redator de um determinado componente pode convidar alguns professores de grande conhecimento e legitimidade para construir, de forma coletiva, a proposta do currículo para tal componente" (BRASIL, 2020, p. 26). Além disso, o documento também recomenda a organização de eventos e a troca constante de email entre as equipes com objetivo de engajar e deixar transparente o processo de implementação.

O Guia prevê a formação continuada (dimensão de número cinco) na forma presencial ou a distância, além do apoio remoto, no qual será possível a interlocução com especialistas, que esclarecerão as dúvidas. Ele apresenta um fluxograma com as atribuições de todos os agentes, ou seja: dos coordenadores estaduais, dos articuladores do regime de colaboração, dos analistas de gestão, dos coordenadores de etapas e dos redatores. A atribuição desses agentes compreende tarefas como articular, mobilizar, apoiar, acompanhar e coordenar.

A respeito da redação preliminar, o Guia destaca (2002, p.30) que ela preze pela clareza, pela unidade e pela coerência, propondo uma progressão das aprendizagens, articulando os 
diferentes componentes, e observando o tempo necessário para trabalho do professor com aluno etc.

De acordo com o Guia Curricular (2020, p. 41), o perfil da equipe central, requer experiência nesse campo, capacidade de liderança e trabalho em equipe, expertise (especialidade) no campo de atuação, participação, e acompanhamento (preferencialmente) do processo de construção curricular. Também se prevê a criação de uma equipe central de gestão, cujo perfil congrega: experiência de planejamento e execução de programas de formação de professores a nível estadual capacidade de liderança, colaboração, articulação e trabalho em equipe; posição sênior dentro da rede em que atua; amplo conhecimento das redes de seu estado; liderança do processo de elaboração e execução dos novos currículos (Coordenadores Estaduais ProBNCC) ou as políticas de formação das redes.

Cabe à equipe central de formação, planejar ações nesse âmbito, cujo processo consiste em seis etapas: 1. delimitação das regiões de atuação; 2 . composição de equipes regionais; 3 . definição dos temas prioritários da formação; 4. definição das modalidades e dos recursos para execução das formações; 5. definição do cronograma das formações nas regiões; 6. definição dos processos de monitoramento e avaliação das formações (BRASIL, 2020, p.44).

As ações voltadas para a formação implicam a definição de temas prioritários, considerando o levantamento das principais inovações estabelecidas pelos novos currículos, ou seja, aquilo que mais gerou mudanças na prática dos professores; também, os resultados e as dificuldades observadas nas primeiras formações com equipes gestoras e professores (BRASIL, 2020, p. 48).

Esse detalhamento do Guia apresentado nos parágrafos anteriores, expressa uma divisão do trabalho que lembra um aparato industrial e sua necessidade de produtividade e eficiência. Para tanto, é necessário o estabelecimento de uma hierarquia, de uma especificação de tarefas, do detalhamento de meios e fins e, principalmente, de mecanismos de controle. Todo o aparato apresentado pelo Guia lembra o sujeito econômico e eficiente, o qual, segundo Marcuse (1999), substitui o indivíduo livre, definido durante os séculos XVI e XVII, como aquele capaz de fazer uso de sua própria razão e de seu pensamento autônomo. Ao contrário desse último, a individualidade eficiente é objeto de organização e coordenação em larga escala e seu desempenho individual é motivado, guiado e medido por padrões que lhes são exteriores e que dizem respeito a tarefas e funções predeterminadas. Dessa forma,

O indivíduo eficiente é aquele cujo desempenho consiste numa ação somente enquanto seja a reação adequada às demandas objetivas do aparato, e a liberdade do indivíduo está confinada à seleção dos meios mais adequados para alcançar uma meta que ele não determinou (MARCUSE, 1999, p. 78).

Nessa citação Marcuse (1999) destaca que o indivíduo eficiente deve adequar as suas reações às necessidades do aparato. Esse princípio é facilmente identificável no Guia Curricular, que vai além das palavras do autor em suas análises sobre o indivíduo eficiente, pois na perspectiva do Guia, não se permite que o sujeito, no caso o professor, defina os meios para alcançar uma meta que lhe foi prescrita, pois essa tarefa foi antecipada pelo 
aparato legal. A anulação do referente é uma forma de ocultá-lo em seu dizer, de bloquear os interlocutores, pois segundo Orlandi (1996, p. 15), no lugar deles existe "[...] um agente exclusivo, o que resulta na polissemia contida (o exagero é a ordem no sentido em que se diz "isso é uma ordem", em que o sujeito passa a instrumento de comando)".

O Guia apresenta a EaD (Educação a Distância) e a mediação tecnológica como possibilidades de formação para além da modalidade presencial. Ele indica a formação nos espaços das escolas. Prevê a possibilidade de parcerias com IEs (Instituições de Ensino Superior) e outros centros de formação. Essas instituições podem realizar gestão e formação, com o acompanhamento da equipe central. Também podem ceder seu corpo técnico e seu espaço físico.

O alinhamento da formação com o Guia, conforme aponta esse documento (2020, p. 56), pressupõe a formação de equipes gestoras nas escolas. Para tanto, sugere que o coordenador ou o diretor da escola lidere esse processo. Dentre as suas responsabilidades encontram-se:

- Planejar e conduzir a formação de professores na escola;

- Conduzir o processo de (re)elaboração dos PPs à luz dos novos currículos;

- Articular a disponibilidade do(s) professor(es) para que participem da formação;

- Acompanhar professores na elaboração e utilização de planos de aula e de avaliações da aprendizagem dos alunos com relação aos novos currículos;

- Formar-se e atualizar-se continuamente sobre os novos currículos e sobre metodologias efetivas de formação continuada, alinhadas às premissas deste Guia (BRASIL, 2020, p.56).

Todas as ações de formação buscam a implementação dos novos currículos, recomendando-se uma média de ao menos 2 horas semanais de formação dos docentes, sejam elas presenciais ou a distância. Cabe às equipes centrais e regionais monitora o cumprimento do cronograma de implantação da formação continuada. A essas equipes também cabe o cumprimento das pautas formativas; a frequência de participação dos participantes (equipes gestoras e professores), o levantamento de necessidades formativas das equipes gestoras escolares e professores, de forma a subsidiar o desenho de novas formações. Para exercer melhor esse papel, o documento recomenda a elaboração de relatórios que indiquem o cumprimento das pautas, a presença dos participantes e as questões levantadas. Recomendase que se realize com os participantes, a cada encontro, a avaliação por meio de formulários estruturados construídos pela equipe central ou equipe regional de gestão (BRASIL, 2020, p.60-61).

Ao se referir aos Projetos Pedagógicos, o Guia afirma que eles devem referendar o processo de escolha do livro didático, sendo que este aspecto merece uma dimensão, a de número seis. Não só o livro, mas os materiais didáticos devem se alinhar com a nova proposta curricular.

Dentre as cinco questões postas pelo Guia (2020, p.77) para a reflexão acerca do livro didático, três delas referendam a implementação da BNCC: a segunda, pergunta se os materiais didáticos disponibilizados abordam competências e habilidades, direitos e objetivos 
previstos na BNCC e pelo novo currículo, a terceira que problematiza as iniciativas que poderão melhorar o novo currículo e a quarta que diz respeito ao trabalho das Secretarias no que tange ao apoio para a melhor escolha e melhor uso dos materiais didáticos em conformidade com o novo currículo.

O Guia (2020, p.81-88) considera como materiais didáticos obras e outros recursos didáticos, tais como: obras didáticas, obras pedagógicas, softwares e jogos educacionais, obras literárias, materiais de reforço e correção de fluxo, planos de aula e atividades, materiais de formação, materiais destinados à gestão escolar, entre outros. Ressalta que $\mathrm{O}$ PNDL (Programa Nacional do Livro Didático) pressupõe a inclusão de outros materiais. A avaliação do material didático além de vários critérios elencados tomará como pressuposto o foco e a coerência com a $\mathrm{BNCC}$, no que se refere às competências, habilidades e à sequência dos tópicos alinhadas com a BNCC.

A partir do domínio e da compreensão da estrutura do currículo, deve-se atentar sobre como o material busca desenvolver não só as habilidades e competências específicas de cada área e componente mas também as dez competências gerais da BNCC e os temas contemporâneos transversais, de forma integrada e interdisciplinar, além de metodologias de aprendizagem alinhadas à proposta do currículo da rede (BRASIL, 2020, p.91).

O livro e os demais materiais didáticos elaborados conforme os parâmetros do Guia Curricular reproduzem a lógica da indústria cultural. Nessa, conforme Adorno e Horkheimer (1985), o espectador não necessita de nenhum pensamento próprio, pois o produto prescreve a reação do consumidor, logrando-o com a promessa do conhecimento.

A educação escolar se emiscui cada vez mais nos mecanismos da indústria cultural. A escola espera, ao confundir escolarização e consumo, adentrar o mundo dos negócios de forma mais eficiente, na medida em que torna os alunos consumidores de uma mercadoria-lição que promete valor de troca e trabalho nãofatigante, divertido e rotineiro como acesso ao conhecimento (GRUSCHKA, 2008, p. 177).

O Guia ressalta que a formação continuada deve definir estratégias para o uso apropriado do material didático, de forma que ele se alinhe com o novo currículo. Ele refere-se ao monitoramento exercido pela comissão de materiais didáticos, a fim de verificar o cumprimento adequado dos aspectos que envolvem essa questão (BRASIL, 2020, p. 101$105)$.

O termo alinhamento define a estruturação de todas as fases do Guia, que pretende familiarizar os professores com a proposta da BNCC, obtendo assim a hegemonia do processo. No entanto, esse fato faz lembrar que existe, segundo Marcuse (1999, p. 92) um abismo "[...] entre a população subordinada e os formuladores dos projetos de racionalização, os planejadores da produção, os que inventam e fazem descobertas que aceleram o progresso tecnológico". 
O Guia Curricular remete à compreensão de Marcuse (1999) acerca da racionalização tecnológica, a qual possibilita as condições necessárias para a criação de uma estrutura comum de experiência para todos (produção, consumo, distribuição, transporte, comunicação). O pensamento e as atividades intelectuais sofrem a infiltração da lógica da racionalidade instrumental, assim elas se tornam uma questão de técnica e de treino. Sob a lógica da implantação do novo currículo, o trabalho educacional consiste em um empreendimento, no qual todos envolvidos devem se comprometer, pois o resultado demanda pela integração total de todas as partes.

O caráter objetivo e impessoal da racionalidade tecnológica, de acordo com Marcuse (1999, p. 99), confere "a dignidade universal da razão" aos grupos burocráticos, a quem os subordinados obedecem tendo a impressão de que o fazem em função de uma racionalidade objetiva.

A racionalidade tecnológica se converte em racionalidade objetiva, camuflando as relações de poder privadas. Sob essas condições, segundo Marcuse (1999, p 99), produção, consumo, distribuição, transporte, comunicação - todos se rendem ao mesmo denominador comum - e a individualidade se torna desnecessária, pois a produção em massa preenche os espaços nos quais a individualidade poderia se afirmar.

Sob a influência de um discurso construído para não deixar brechas e sob o prisma da classificação e da organização, o Guia Curricular pretende convencer os professores de que é intransponível.

\section{A Conciliação na BNCC do Ensino Fundamental e no seu Guia de Implementação}

A conciliação é uma característica da sociedade capitalista contemporânea e ela foi magistralmente ilustrada por Adorno e Horkheimer (1985), na Dialética do esclarecimento, mais especificamente no capítulo em que os autores tratam da indústria cultural. O conceito de indústria cultural expressa essa oposição, pois, o primeiro termo, no contexto da Teoria Crítica, remete ao mundo da necessidade, da autopreservação da vida e aos interesses imediatos; enquanto o segundo termo, transcende o imediatismo e o mundo da necessidade. A indústria cultural, ao atuar como uma organizadora e administradora da cultura da sociedade, concilia coisas irreconciliáveis, dentre as quais: cultura e diversão, arte leve e arte séria, massificação e diferenciação, totalidade e particularidade. No que tange à BNCC e ao Guia Curricular, esses dois últimos pares manifestam-se no processo de análise com base na Teoria Crítica. Eles são acrescidos de outros pares: liberdade (protagonismo dos professores) e autoridade (especialidade), igualdade e desigualdade.

A expectativa da BNCC é a de que ela

[...] ajude a superar a fragmentação das políticas educacionais, enseje o fortalecimento do regime de colaboração entre as três esferas de governo e seja balizadora da qualidade da educação. Assim, para além da garantia de acesso e 
permanência na escola, é necessário que sistemas, redes e escolas garantam um patamar comum de aprendizagens a todos os estudantes, tarefa para a qual a BNCC é instrumento fundamental (BRASIL, 2018, p. 8).

$\mathrm{Na}$ citação anterior, a qualidade da educação nacional tem como baliza a BNCC, na medida em que ela integra as diferentes unidades e esferas do poder da federação. Dessa forma, as desigualdades provenientes das condições materiais são enfrentadas mediante uma política curricular única, cuja ausência é vista como fator preponderante das mazelas educacionais e a unidade é utilizada como antídoto para a diferença de desempenhos e resultados nas avaliações educacionais.

A BNCC reforça a ideia da meta 7 do PNE de focar na aprendizagem como estratégia para fomentar a qualidade da educação. Para ela, "as competências e diretrizes são comuns, os currículos são diversos" (BRASIL, 2018, p. 11). A organização logística para a implementação da BNCC expressa o poder da totalidade, da autoridade e dos especialistas sobre a periferia e sobre o diferente.

Nesses termos, a BNCC e seu processo de implementação parecem desconsiderar que a diversidade é uma construção social, histórica e cultural. Conforme Moreira e Candau (2007, p. 31) para a elaboração de um currículo que valorize a diversidade cultural existente, é necessário que se busque o entendimento de que as diferenças e desigualdades não são naturais, mas sim, são construções históricas da humanidade e que podem ser até mesmo serem transformadas.

Segundo Moreira e Candau (2007, p. 27-28), se determinado grupo compartilha uma cultura, compartilha também "significados construídos, ensinados e aprendidos nas práticas de utilização da linguagem", que são "produzidos e compartilhados em grupo". Nesta perspectiva, o currículo pode ser considerado como "um conjunto de práticas em que os significados são construídos, disputados, rejeitados, compartilhados".

Entende-se que todo currículo comporta a cultura e que essa, conforme as diferentes perspectivas teóricas, sempre traz no seu âmago a ideia de diversidade e de disputa. Cabe então perguntar: "que forças fazem com que o currículo oficial seja hegemônico e que forças fazem com que esse currículo aja para produzir identidades sociais que ajudam a prolongar as relações de poder existentes?" (MOREIRA; SILVA, 2002, p.29).

O Guia (2020, p. 114) sugere como consulta e utilização os seguintes referenciais: o Glossário de Terminologia curricular da UNESCO, que é apontado como. material de referência para a redação, a interpretação, a implementação e avaliação curricular, o Britsh Columbia, as especificações de desenho curricular que moldaram o conteúdo do currículo australiano e os padrões curriculares dos EUA.

A dimensão de número quatro (Formação Continuada) prevê a oportunização para todos os professores, a partir de 2019, de formação continuada para o trabalho com os novos currículos. Nesse contexto, o Guia (2020, p. 37) problematiza as premissas que devem fundamentar a formação continuada voltada para o desenvolvimento das aprendizagens dos novos currículos, a garantia do alcance das ações formativas às equipes gestoras das escolas e dos professores das redes, as necessidades dos professores, equipes gestores e formadores 
para implementação de novos currículos e a execução da formação continuada para professores e equipes gestoras, considerando prioridades e recursos disponíveis.

A formação continuada deve se apoiar no desenvolvimento de competências e habilidades e no desenvolvimento de metodologias ativas. A esse respeito o Guia (2020, p. 39), apresenta uma concepção de protagonismo do professor, que se relaciona com a contemplação de aspectos relacionados ao dia a dia de seu trabalho. Nesse sentido, o protagonismo é interpretado como a centralidade que as orientações curriculares atribuem ao trabalho cotidiano do professor, enquanto o elemento executor, que objetivará toda a elaboração teórica pensada pelas equipes que representam as sete dimensões do processo de implementação da BNCC.

O conteúdo do processo de formação continuada também deve se pautar no trabalho colaborativo, expresso no compartilhamento das boas práticas de favorecimento das condições de aprendizagem, conforme estabelecidas pelas orientações curriculares. A formação ainda contempla como foco o desenvolvimento de conhecimentos (pedagógico, do conteúdo em si e da mobilização desse conhecimento pelo estudante). Além disso, os resultados educacionais devem orientar a metodologia de formação, “[...] para que ela seja contextualizada e direcionada para as necessidades reais dos professores e dos estudantes (Brasil, 2020, p.39). Portanto, a formação mira os resultados e o planejamento do professor no sentido de alcançá-los. A composição de uma equipe central, composta por Coordenadores Estaduais de Currículo e lideranças das ações de formação continuada, é o primeiro passo para o início do processo de formação.

A concepção de formação continuada exposta pelo Guia integra-se ao trabalho, conciliando-se com ele. Porém, na concepção da Teoria Crítica, formação e trabalho são opostos irreconciliáveis, uma vez que essa relação pressupõe que a primeira faça concessões em relação à segunda. Enquanto a formação remete ao mundo da cultura e do espírito, procurando transcender o imediato e o mundo da necessidade, o trabalho, tende a sucumbir ao imediatismo e ao reino da necessidade, especialmente no contexto da objetividade social, permeada pelas relações de troca.

A tentativa da implantação da BNCC em articular esses dois âmbitos, oportuniza o treinamento, conforme os parâmetros do Guia, pois a tendência imperativa da sociedade consiste na adaptação, ou seja, no atendimento das demandas econômicas. Nesse caso, ocorre o conformismo e a falsificação da formação (semiformação). A resistência a esse processo, enquanto possibilidade advinda das contradições da história, prescinde da reflexão crítica acerca da semiformação, que nesse caso se expressa pela política de formação voltada para a padronização e para a unidade, a qual compromete a essência do processo formativo, que se encontra na diferenciação, na pluralidade e na tensão entre a realidade e o pensamento. Para tanto, as escolas precisarão fortalecer o debate no contexto de sua realidade, de suas especificidades, confrontando a teoria com a prática, na tentativa de mantê-las em um constante processo de interlocução crítica.

Ao se referir à dimensão de número cinco, que trata da revisão dos projetos pedagógicos, o Guia (2020, p.65) destaca a importância dessa etapa uma vez que prepara para a chegada às escolas, dos novos currículos alinhados com a BNCC. A revisão dos projetos pedagógicos 
"REPRESENTA A VALORIZAÇÃO DA IDENTIDADE DAS ESCOLAS EM CONSONÂNCIA COM AS NOVAS PROPOSTAS PEDAGÓGICAS" (grifos do documento).

Assim, o Guia de Implementação (2020) pretende solucionar uma complicada equação que envolve a relação entre a identidade da escola e a integração à proposta da BNCC. Para a Teoria Crítica, a identidade não se fortalece na generalidade, mas na diferença e na autonomia, no conflito entre o pensamento e a realidade, que na concepção dos referidos documentos, não é entendido como algo salutar, uma vez que a resistência é vista como um empecilho ao alinhamento dos professores com a proposta curricular.

No Guia Curricular (2020), o projeto pedagógico é concebido como um documento que projeta e orienta as ações que acontecem durante o ano letivo. Assim, ele precisa ser revisto no contexto da homologação da BNCC, a fim de assegurar os direitos e objetivos de aprendizagem de todas as crianças e jovens da Educação Básica. Para que isso aconteça, é importante que se estabeleça um processo de parceria entre equipe gestora da escola, professores e demais integrantes da comunidade escolar, com apoio da Secretaria de Educação (BRASIL, 2020, p.65).

No contexto de implementação dos novos currículos, a revisão dos PPs torna-se ainda mais relevante. Isso porque o processo de revisão do documento precisa garantir a apropriação do novo currículo e a reflexão sobre como os novos marcos conceituais, a abordagem curricular e os direitos e aprendizagens propostos contribuem para mudanças nas práticas pedagógicas e no cotidiano escolar, dentro e fora da sala de aula (BRASIL, 2020, p. 67).

O Guia (2020) apresenta uma concepção mais avançada do PP (Projeto Pedagógico), mas que parece diluir-se na concepção anterior e na necessidade constante de se manter o alinhamento com as políticas curriculares centrais, mediante a formação, o controle e o monitoramento.

O PP é um documento central, pois fortalece a identidade da escola, esclarece sua organização, traz as concepções, os marcos conceituais, as estratégias de ensino e de avaliação que deverão nortear a organização do cotidiano, as práticas e documentações pedagógicas, define objetivos para a aprendizagem dos alunos e, principalmente, estabelece estratégias e ações para que a escola consiga atingilos. O projeto pedagógico é um documento único e de autonomia de cada escola e, portanto, pode apresentar diferentes estruturas e elementos. A seguir, sugeremse alguns componentes importantes que as Secretarias podem indicar aos gestores escolares para apoiá-los no processo de revisão (BRASIL, 2020, p. 70).

A necessidade de monitoramento compromete a caráter identitário e a liberdade das escolas em decidir sobre o seu Projeto Político Pedagógico. A supressão do termo Político é um indicativo das intencionalidades voltadas para a neutralidade científica e para a 
necessidade de integrar todas as instâncias federativas e todas as escolas a um projeto comum. O monitoramento pressupõe:

- Acompanhar e monitorar o avanço das escolas na revisão de seus Pps, - Agendar visitas presenciais às escolas para apoiar a equipe gestora e acompanhar o processo de planejamento da revisão do projeto pedagógico.

- Marcar encontros periódicos entre os gestores escolares de todas as escolas e a equipe técnica da Secretaria para compartilharem o processo, proporcionando a troca de experiências e apoios necessários.

- Oferecer espaços e momentos da Secretaria para, periodicamente, tirar dúvidas e auxiliar as equipes escolares na revisão de seus PPs. Pode-se criar também um canal digital para tirar dúvidas da equipe gestora e da comunidade escolar sobre o processo de revisão (BRASIL, 2020, p. 74).

Todo esse aparato lembra os aforismos de número 81 e 82, nos quais Adorno (1993) se refere à hierarquização de urgências, seguindo os critérios do planejamento econômico, que definem o que é relevante segundo os pontos de vista organizacionais. A importância como critério do pensamento acaba por fixá-lo e fazê-lo abdicar da autorreflexão. Ao seguir os critérios organizacionais, o pensamento anula a não identidade em favor da aproximação com o idêntico. Entende-se que o Guia Curricular procede dessa forma, procurando uma zona de segurança por meio da aproximação de todos em torno de um mesmo projeto, pois "A distância não é nenhuma zona de segurança, e sim um campo de tensões” (ADORNO, 1993, p. 11).

A distância consiste na valorização dos conflitos que ocorrem cotidianamente na escola, no confronto entre o discurso compacto do Guia e as relações concretas que professoras, professores, alunos, equipe pedagógica e toda a comunidade escolar estabelecem. São elas que promoverão o terreno para as contradições entre o que foi pensado e o que é vivido. Esse esforço de distanciamento oportuniza a autorreflexão crítica e a não identificação, que consistem em possibilidades de resistência à semiformação.

\section{Considerações finais}

A falsificação da formação na BNCC do Ensino Fundamental e no seu Guia de Implementação se expressa por meio da normatização, do nominalismo, da hierarquização e do enfraquecimento da autonomia e do protagonismo docente. Além disso, os documentos tendem ao verticalismo, à antecipação das ideias e das ações, culminando em uma reforma controladora, que busca o consenso e a anulação da crítica. Ao procederem dessa forma, os referidos documentos atacam a autonomia docente, cuja condição é vital ao processo formativo.

A BNCC e o Guia, quando chamam os professores à participação, fazem-no com o objetivo de que eles resolvam problemas relacionados às suas orientações curriculares. No entanto, o questionamento e a indagação acerca dos pressupostos e direcionamentos práticos 
da BNCC podem resultar no tensionamento entre o pensado e o vivido, entre o todo e as partes.

A insistência em alinhar todas as ações escolares com a proposta da BNCC, dificulta a possibilidade de escapar de sua lógica, mas não a inviabiliza, visto que existe um espaço para a contradição entre o vivido e o pensado, entre o real e o legal. $O$ formalismo legal talvez desperte nos professores a necessidade de fortalecer os espaços e os processos decisórios que se constituem no cotidiano escolar.

A forma como a BNCC compreende a contextualização do currículo, ou seja, como mobilização de aprendizagens e vinculada à tecnologia, afasta-se das condições reais das escolas, das suas características específicas e do perfil dos educandos, que nem sempre dispõem dos recursos tecnológicos para a utilização das redes sociais como ferramenta de aprendizagem. Por trás dessa ideia, existe a concepção de que o modelo tradicional é ultrapassado, constituindo-se em empecilho às mudanças e à promoção da aprendizagem. No entanto, segundo Adorno (2010), a educação tradicional constitui-se no parâmetro de formação, na medida em que lembra a existência de pressupostos e a possibilidade de resistência ao excesso de realismo. A ênfase no conhecimento a serviço da operação enfraquece a capacidade conceitual e teórica, na qual é possível transcender o imediatismo e a tecnificação do mundo.

Outro aspecto relevante é aquele que se refere à relação entre a identidade e a diferença. Entende-se que a BNCC, na tentativa de promover a qualidade de ensino, acentua o primeiro termo em detrimento do segundo. Sendo assim, a Base Comum Curricular expressa a ideia de uma orientação geral e unificada que integra as diferentes instâncias da educação escolar em torno de um mesmo projeto, o que também resultaria na equidade.

A integração é um dos elementos fundantes da sociedade capitalista e de sua racionalidade, que aparece nos documentos analisados por meio do termo "alinhamento", cujo significado expressa a ideia de colocar em uma fila, em linha reta. Tal ideia expressa sua contradição uma vez que uma fila pressupõe uma linearidade, mas também um ordenamento, que estabelece os primeiros e os últimos.

De acordo com Sena (2019), grandes editoras já montaram seus kits, adequando seus materiais à BNCC, antes mesmo de os professores entenderem as mudanças propostas. Assim como "os cursos de formação continuada, a pós-graduação em EAD, as palestras gratuitas nos eventos de prefeitos e governadores", "as consultorias sem custos para as secretarias de educação" que "no fim das contas, comandam um grande e rentável negócio chamado educação pública" (SENA, 2019, p. 23).

Esse aspecto aponta para a semelhança entre a BNCC e a indústria cultural - o que também pode ser entendido como um instrumento a serviço da sua promoção - na medida em que o referido documento fomentará uma corrida das editoras e das empresas que elaboram materiais didáticos e softwares educativos.

A indústria cultural, segundo Adorno e Horkheimer (1985), confere a tudo, um ar de semelhança, expande a lógica do sistema, promove o nivelamento, absorve a espontaneidade e o pensamento do público, classifica os bens em categorias, é esquemática e antecipatória. Assim, a obra deixa de ser o veículo da ideia, priorizando o efeito e o detalhe técnico. 
Qualquer semelhança com a BNCC não é mera coincidência.

A BNCC opera sob a mesma lógica da sociedade, na tentativa de converter tudo ao mesmo denominador comum, tal qual acontece na sociedade, pois nessa, segundo Adorno (1994), a produção, a distribuição e o consumo são administrados conjuntamente. Dessa forma, a existência social encontra-se completamente mediatizada em si e "o momento da mediação acaba sendo deformado por sua totalidade" (Adorno, 1994, p. 74).

Sob essas condições, é possível afirmar que a BNCC consiste em uma forma de automatizar o sistema, convertendo todo o processo educativo à sua ordem. No entanto, Adorno (1994) lembra que o feitiço por mais insuportável que seja, é apenas feitiço e que o papel da sociologia, que neste estudo podemos estender para o campo da educação, consiste em não sucumbir ao caráter universal do fetiche - o que consiste no primeiro passo para quebrá-lo. Para tanto, o exercício da crítica é de fundamental importância, sendo que ele orientou todo o processo de análise da BNCC do Ensino Fundamental e do seu Guia de Implementação.

\section{Referências}

ADORNO, Theodor Wiesengrund; HORKHEIMER, Max. Dialética do esclarecimento. Rio de Janeiro: Zahar, 1985.

ADORNO, Theodor Wiesengrund. Minima Moralia: reflexões a partir da vida danificada. São Paulo: Ática, 1993.

ADORNO, Theodor Wiesengrund. Capitalismo Tardio ou Sociedade Industrial. In: COHN, Gabriel (Org.). Adorno: Sociologia. São Paulo: Ática, 1994, p. 62-75.

ADORNO, Theodor Wiesengrund. Educação e emancipação. São Paulo: Paz e Terra, 1995.

ADORNO, Theodor Wiesengrund. Teoria Estética. Lisboa: Edições 70, 2006.

ADORNO, Theodor Wiesengrund. Introdução à Sociologia. São Paulo: UNESP, 2008.

ADORNO, Theodor Wiesengrund. Teoria da Semiformação. In: PUCCI, Bruno; ZUIN, Antônio Álvaro Soares; LASTÓRIA, Luiz Antônio Calmon Nabuco (Orgs.). Teoria Crítica e Inconformismo: novas perspectivas de pesquisa. Campinas: Autores Associados, 2010, p.7-40.

BRASIL. Ministério da Educação. Base Nacional Comum Curricular. Brasília, 2018. Disponível em: http://basenacionalcomum.mec.gov.br/images/BNCC_EI_EF_110518_versaofinal_site.pdf. Acesso em: 20 jun. 2020.

BRASIL. Ministério da Educação. Guia de Implementação da Base Nacional Comum Curricular. Brasília, $2020 . \quad$ Disponível em: https://implementacaobncc.com.br/wpcontent/uploads/2020/02/guia_implementacao_bncc_atualizado_2020.pdf. Acesso em: 29 ago. 2020.

DESIGNER. In: Dicionário Online de Português. Disponível em: https://www.dicio.com.br/designer/. Acesso em: 19 out. 2020.

DUARTE, Newton. As pedagogias do "aprender a aprender" e algumas ilusões da assim chamada sociedade do conhecimento. Revista Brasileira de Educação, n. 18, p. 135-151, Set/Out/Nov/Dez. 2001.

EVANGELISTA, Olinda. Apontamentos para o trabalho com Documentos de Política Educacional. In: ARAÚJO, Marcos de Lima; RODRIGUES, Doriedsosn (Orgs.). A pesquisa em: Trabalho, Educação e Políticas Educacionais. Campinas: Alínea, 2012, p. 51-71.

FUZAL, Ângela Francine; MIRANDALL, Flávia Danielle Sordi Silva.Tecnologias digitais, letramentos e 
gêneros discursivos nas diferentes áreas da BNCC: reflexos nos anos finais do ensino fundamental e na formação de professores. Revista Brasileira de Educação, Rio de janeiro, v. 25, p. 1-26, março. 2020. Disponível em: https://www.scielo.br/pdf/rbedu/v25/1809-449X-rbedu-25-e250009.pdf. Acesso em: 16 out. 2020 .

GRUSCHKA, Andréas. Escola, didática e indústria cultural. In: DURÃO, F. A; ZUIN, A; VAZ, A. F. (Orgs.). A indústria cultural hoje. São Paulo: Boitempo, 2008. p. 173-183.

HORKHEIMER, Max. Eclipse da razão. São Paulo: Centauro, 2002.

MARCUSE, Herbert. As novas formas de controle. In: MARCUSE, H. A ideologia da sociedade industrial: o homem unidimensional. Rio de Janeiro: Zahar, 1973, p.23-37.

MARCUSE, Herbert. A dimensão estética, In: MARCUSE, H. Eros e a civilização. Rio de Janeiro: LTC, 1995, p. 156-173.

MARCUSE, H. Sobre o caráter afirmativo da cultura. In: MARCUSE, H. Cultura e Sociedade, v. 1. São Paulo: Paz e Terra, 1997, p. 89-136.

MARCUSE, H. Comentários para uma definição de cultura. In: MARCUSE, H. Cultura e Sociedade, v. 2. São Paulo: Paz e Terra, 1998, p. 153-174.

MARCUSE, H. Algumas implicações sociais da tecnologia moderna. In: MARCUSE, H. Tecnologia, guerra e fascismo. São Paulo: UNESP, 1999, p.73-104.

MOREIRA, A. F. B; CANDAU, V. M. Indagações sobre currículo: currículo, conhecimento e cultura. Brasília: Ministério da Educação, Secretaria de Educação Básica 2007.

MOREIRA, A, F. B; SILVA, T, T. Sociologia e teoria crítica do currículo: uma introdução. São Paulo: Cortez, 2002, p. 7-31.

ORLANDI, Eni Pucciinelli. A linguagem e seu funcionamento: as formas do discurso. São Paulo: Pontes, 1996.

SENA, Ivânia Paula Freitas de Souza. A BNCC é lei, o que fazer. In: UCHOA, Antonio Marcos da Conceição; SENA, Ivânia Paula Freitas de Souza (Orgs). Diálogos Críticos: BNCC, educação, crise e luta de classes em pauta. Porto Alegre, 2019, p.97-106. Disponível em: https://www.editorafi.org/640bncc. Acesso em: 26 fev. 2020.

\section{Correspondência}

Josele Fogaça: Mestre em Educação pela Universidade Estadual do Centro-Oeste (UNICENTRO) na Linha de Pesquisa Políticas Educacionais, História e Organização Escolar. Docente da Rede Municipal de Educação do Município de Inácio Martins - PR.

E-mail: oselefogaca@gmail.com

Luciane Neuvald: Doutora em Educação Escolar pela Universidade Estadual Paulista "Júlio de Mesquita Filho" (UNESP - Araraquara). Professora Associada do Departamento de Pedagogia e do Programa de Pós-Graduação em Educação da Universidade Estadual do Centro-Oeste (UNICENTRO), Guarapuava - PR. Integra a Linha de Pesquisa Políticas Educacionais, História e Organização Escolar. Coordena o Grupo de Pesquisa Sociedade, Formação, Cultura e Tecnologia e desenvolve pesquisas que discutem a formação no âmbito da Teoria Crítica da Escola de Frankfurt.

E-mail: luneuvald@terra.com.br 
Texto publicado em Currículo sem Fronteiras com autorização dos autores. 